\title{
"UMA ARQUEOLOGIA QUE DESPEDAÇA SEUS ÍDOLOS": CRÍTICA À HISTÓRIA EM AS PALAVRAS E AS COISAS
}

\author{
"AN ARCHEOLOGY THAT SMASHES ITS IDOLS": CRITICAL TO HISTORY IN THE ORDER OF \\ THINGS
}

Lorena de Paula Balbino*

\section{RESUMO}

Desde a recepção de seus primeiros escritos, a relação de Foucault com a história tem sido interpretada de modo ambíguo. Apesar de seus trabalhos filosóficos terem um caráter fortemente historiográfico, a partir da publicação de As palavras e as coisas, o filósofo é visto tanto como aquele que recusa a história quanto como aquele que a revoluciona. Esse trabalho trata da recepção que teve a obra As palavras e as coisas, quando de seu lançamento, e procura investigar qual o caráter da crítica que recai sobre a noção de história foucaultiana. Objetivamos, ainda, acentuar de que forma a arqueologia foucaultiana pôde sinalizar os limites da operação historiográfica por meio de uma análise descontínua da crítica à origem. PALAVRAS-CHAVE: Foucault. Historiografia. Arqueologia. Descontinuidade. Episteme.

\begin{abstract}
Since the reception of his first writings, Foucault's relation with history has been interpreted ambiguously. Despite the strong historical character of you philosophical works since the publishing of The order of things, the philosopher is seen both as the one who refuses history and as the one who revolutionizes it. This paper treats about the reception of the work The order of things since its release, and proposes to investigate which is the character of the critique that implies over the foulcauldian notion of history. We also aim to point the way foucault's archeology could sinalize the limits of the historiographical operation through a discontinuous analysis of the critique of the origin.
\end{abstract}

KEYWORDS: Foucault. Historiography. Archeology. Discontinuity. Episteme.

\footnotetext{
* Mestra em Filosofia pela Universidade Estadual de Londrina. Doutoranda em Filosofia pela Universidade Federal de São Carlos. E-mail: lorenabalbino_@hotmail.com.
} 
Em conferência realizada quase quatro anos após a morte de Michel Foucault Gérard Lebrun destaca o caráter combativo da obra As palavras e as coisas. Lebrun ressalta que o livro foi recebido não como um ensaio que traria a originalidade de um novo método, mas como uma agressão (LEBRUN, 1989, p. 33). Enquanto Lebrun recorda a obra de 1966 como uma recusa da fenomenologia, na época de seu lançamento o livro foi visto muito mais como um ataque direto ao marxismo. Em 1968, por ocasião do lançamento da tradução francesa de Reason and Revolution: Hegel and the Rise of Social Theory de Herbert Marcuse, Robert Castel escreve no prefácio do livro que As palavras e as coisas é um ataque direto de Foucault a obra do filósofo alemão (CASTEL, 1968, p. 34). No mesmo ano Jacques Milhau escreve nos Cahiers du communisme que a obra de Foucault, ao se servir de uma "ideologia" neonietzschiana, é anti-histórica e por isso presta um favor a classe dominante ${ }^{1}$. Todos esses problemas se estenderão ao percurso filosófico de Foucault e farão com que filósofos contemporâneos possam dizer que um combate com Marx é coextensivo a toda sua obra ${ }^{2}$.

Contudo, a crítica de maior repercussão à época talvez seja a de Jean Paul Sartre. O autor de $O$ ser e o nada acredita que o livro de Foucault toma o marxismo como alvo e se constitui como uma nova ideologia levantada pela burguesia contra Marx. O ponto nevrálgico da crítica sartreana, e também dos marxistas da época ${ }^{3}$, é o tratamento dado a história nesse livro que pretende fazer a arqueologia das ciências humanas. Para Sartre As palavras e as coisas é o livro representante do que ele acredita ser uma tendência dominante na época que tem por característica a recusa da história. A esse respeito Sartre nos diz o seguinte:

Mas Foucault não nos diz o que seria mais interessante: a saber, como cada
pensamento é construído a partir dessas condições, nem como os homens passam de
um pensamento à outro. Ele precisaria para isso fazer intervir a práxis, portanto à
história, e é precisamente o que ele recusa. Certamente, sua perspectiva permanece
histórica. Ele distingue as épocas, um antes e um depois. Mas substitui o cinema
pela lanterna mágica, o movimento por uma sucessão de imobilidades. O sucesso de
seu livro prova o que era esperado. Ora, um pensamento realmente original jamais é

1 “O preconceito anti-histórico de Michel Foucault só se sustenta graças a uma ideologia neonietzschiana que serve muito bem, perceba ele ou não, aos desígnios de uma classe cujo interesse é mascarar as vias objetivas do futuro" (MILHEU apud ERIBON, 1990, p. 166).

2 "Formularei a hipótese de que, sob formas constantemente renovadas, um verdadeiro combate com Marx é coextensivo a toda a obra de Foucault, e uma das molas essenciais de sua produtividade: combate já engajado no momento em que escreve a Histoire de la folie (posto que, como oportunamente lembrado por P. Macherey em um artigo recente, é na inversão de sua adesão inicial do marxismo, concebido como uma "critica concreta" da alienação, que o faz procurar as razões pelas quais, desde então, ele é desconfiado como a peste de tudo o que veio do materialismo dialético); combate ainda aberto depois de La volonté de savoir como testemunha os extratos do curso, artigos e conferências dos anos oitenta" (BALIBAR, 1989, p. 55).

${ }^{3}$ Podemos citar, juntamente com a crítica já referida de Jacques Milheu e Sartre, o artigo de Jeannete Colombel, Les mots de Foucault et les choses publicado na revista do Partido Comunista Francês Le Nouvelle Critique de abril de 1967, que também dá ênfase ao tratamento dado a história por Foucault. 
esperado. Foucault dá as pessoas o que elas precisavam: uma síntese eclética em que Robbe-Grillet e o estruturalismo, a linguística, Lacan, Tel Quel são utilizados alternadamente para demonstrar a impossibilidade de uma reflexão histórica. (SARTRE, 2003, p. 67-68).

Mas por que a ênfase das críticas recai sobretudo na história e o que faz a obra de Foucault ser reconhecida primordialmente como anti-histórica? Talvez a resposta esteja na retirada do homem de seu lugar de sujeito histórico.

Em seu livro de 1966, As palavras e as coisas, Foucault faz a arqueologia das condições de possibilidade historicamente constituídas pelas quais se fez necessário certa forma de pensamento. A época clássica é então o verdadeiro reino da representação em que os saberes são regidos sob os modelos da mathesis universalis (princípio de ordenação) e da taxinomia (princípio de classificação). Nesse período a ordem do pensamento isola o mundo das coisas do mundo das palavras. Na medida em que as palavras devem representar as coisas, o conhecimento é classificatório, ou seja, ele compara, ordena e classifica fazendo com que a linguagem tome por função formar um quadro do mundo. Nesse quadro possível reina a ordem das identidades e das diferenças.

Porém, algo muda na configuração discursiva na passagem do século XVIII para o XIX. A profundidade dos objetos emerge e faz com que eles não possam mais ser analisados a partir da representação e de sua análise das identidades e das diferenças. No entanto, não se deve interpretar essa mudança como resultado de um maior rigor científico. O nascimento das ciências empíricas significa uma incapacidade da representação em dar conta de novos objetos. Mais do que isso, trata-se agora de examinar as condições que permitem a constituição de um campo de representações. O que acontece segundo Foucault: "É um acontecimento radical que se reparte por toda a superfície visível do saber e cujos signos, abalos, efeitos, podem-se seguir passo" (FOUCAULT, 2002, p. 298).

A ruptura que se dá nesse período encerra o saber num espaço novo que toma a forma de uma antropologia. É nesse momento que vemos surgir a figura do homem:

\footnotetext{
Quando a história natural se torna biologia, quando a análise das riquezas se torna economia, quando sobretudo a reflexão sobre a linguagem se faz filologia e se desvanece esse discurso clássico em que o ser e a representação encontravam seu lugar-comum, então, no movimento profundo de uma tal mutação arqueológica, o homem aparece com sua posição ambígua de objeto para um saber e de sujeito que conhece [...] (FOUCAULT, 2002, p. 430).
} 
Desse modo, ao ser tematizado por essas ciências o homem tornou-se objeto do saber. O homem e sua finitude, é esse o tema central dessas ciências empíricas. O que aparece nelas é a finitude do homem falando, trabalhando e vivendo. A concretude de sua existência é determinada pelo trabalho, pela vida e pela linguagem. Desde que o homem dá conta de si mesmo ele percebe-se através dos saberes dessas ciências:

Todos esses conteúdos que seu saber lhe revela exteriores a ele e mais velhos que seu nascimento antecipam-no, vergam-no com toda a sua solidez e o atravessam como se ele não fosse nada mais do que um objeto da natureza ou um rosto que deve desvanecer-se na história (FOUCAULT, 2002, p. 432).

Nesse cenário da analítica da finitude uma confusão se torna aparente: o homem é um estranho duplo empírico-transcendental. Surge um homem que ao mesmo tempo que é fundamento do saber, também se constituiu como objeto desse saber. A ambiguidade da noção moderna de homem, analisado como objeto empírico pelas ciências e como sujeito transcendental pela filosofia, evidenciam a sua frágil constituição. Em As Palavras e as Coisas, Foucault analisa a concepção de homem a partir do exterior do discurso filosófico, recusando desse modo tomá-lo como categoria intemporal.

$\mathrm{Na}$ ordem clássica algo como uma "ciência do homem" não era possível, pois, a episteme dominante, com suas regras próprias, não permitia que a existência humana fosse posta em questão por ela própria. O discurso tratava de adequar a representação e o ser:

\footnotetext{
O discurso que, no século XVII, ligou um ao outro o 'Eu penso' e o 'Eu sou' daquele que o efetivava - esse discurso permaneceu, sob uma forma visível, a essência mesma da linguagem clássica, pois o que nele se articulava, de pleno direito, eram a representação e o ser. A passagem do "Eu penso" ao "Eu sou" realizava-se sob a luz da evidencia, no interior de um discurso cujo domínio e cujo funcionamento consistiam por inteiro em articular, um ao outro, o que se representa e o que é. Não há, pois, que objetar a essa passagem nem o que o ser em geral não está contido no pensamento, nem que este ser singular tal como é designado pelo "Eu sou" não foi interrogado nem analisado por si próprio. Ou, antes, essas objeções podem realmente nascer e fazer valer seu direito, mas a partir de um discurso que é profundamente outro e que não tem por razão de ser o liame entre a representação e o ser; só uma problemática que contorne a representação poderá formular semelhantes objeções. Mas, enquanto durou o discurso clássico, uma interrogação sobre o modo de ser implicado pelo Cogito não podia ser articulada" (FOUCAULT, 2002, p. 429-430).
}

Se o homem é, então, essa reduplicação empírico-transcendental não é mais possível que ele se dê "na transparência imediata e soberana de um cogito" (FOUCAULT, 2002, p. 445). Há algo que escapa, que transborda o pensamento e inaugura o lugar do desconhecido. 
Por ser esse duplo empírico-transcendental o homem se interrogará a partir daquilo que lhe escapa. Nesse momento não se trata mais de saber de que modo pode ocorrer que a experiência dê lugar a juízos necessários mas como pode ocorrer que o homem pense o que não pensa. Ou seja, como pode ocorrer que o homem seja objeto de uma linguagem que se formou sem ele, de um trabalho cujas normas lhe são impostas e de uma vida cuja experiência transborda o imediatamente dado. Foucault dirá que essa região do desconhecido compreende um quádruplo deslocamento em relação a questão kantiana: no lugar da verdade, o ser; no lugar da natureza, o homem; o desconhecimento primeiro ao invés de uma possibilidade de conhecimento; e, por fim, a consciência filosófica de um domínio de experiências nãofundadas onde o homem não se reconhece ao invés do caráter não-fundado da filosofia frente a ciência (FOUCAULT, 2002, p. 446).

Nesse momento o tema do cogito reaparece no pensamento contemporâneo. Fora através do erro, da ilusão, do sonho e da loucura que Descartes vislumbrou a possibilidade de não serem pensamentos. Na modernidade, ao contrário, a relação entre o pensamento e o que não é pensamento tem de ser retomado. Nessa rearticulação do cogito ele não será mais:

\footnotetext{
a súbita descoberta iluminadora de que todo o pensamento é pensado, mas a interrogação sempre recomeçada para saber como o pensamento habita fora daqui, e, no entanto, o mais próximo de si mesmo, como pode ele ser sob as espécies do nãopensante. Ele não reconduz todo o ser das coisas ao pensamento sem ramificar o ser do pensamento até na nervura inerte do que não pensa" (FOUCAULT, 2002, p. 447).
}

Desse modo, o cogito não conduz a evidencia do ser, o "Eu penso" não será garantia do "Eu sou". O cogito se abre para outras interrogações em que o ser é questão central. A relação entre o ser e o pensamento tem agora de levar em conta sua relação e articulação com o impensado. O pensamento reflexivo perde seu privilégio no momento em que o homem surge no campo do saber. A partir desse momento a modernidade se coloca a tarefa de pensar até o que ao homem não lhe é dado na consciência. $\mathrm{O}$ inconsciente e as formas do impensado tornam-se objetos para o pensamento científico e, segundo Foucault, todo o pensando moderno será atravessado pela lei de pensar o impensado (FOUCAULT, 2002, p. 451).

A arqueologia de Foucault denuncia o esgotamento da consciência como constituição da experiência possível, assim como de uma unidade e identidade presente no sujeito. O anúncio da morte do homem, resultado da problematização do próprio conceito de homem, 
situa nas ciências da vida, do trabalho e da linguagem o homem despido de um jogo de verdade e marcado por uma descontinuidade constitutiva.

A ruptura na história do pensamento evidenciada pelo arqueólogo do saber promove um novo modo do fazer histórico em que não importa quem fala, quais influências recebe ou a que posicionamento teórico segue. Segundo Deleuze (2013, p. 16):

\begin{abstract}
Não é necessário ser alguém para produzir um enunciado, e o enunciado não remete a nenhum cogito, nem a algum sujeito transcendental que o tornasse possível, nem sequer um Eu que o pronunciasse pela primeira vez (ou o recomeçasse), nem Espírito do Tempo a conservá-lo, propaga-lo e recortá-lo. Existem, é claro, 'lugares' do sujeito para cada enunciado, por sinal bastante variáveis. Mas precisamente porque o enunciado é o objeto específico de um acúmulo através do qual ele se conserva, se transmite ou se repete. O acúmulo é como a constituição de um estoque, não é o contrário da raridade, mas efeito dessa mesma raridade. Por isso, substitui as noções de origem, e de retorno à origem: tal como a memória bergsoniana, o enunciado se conserva em si, em seu espaço, e vive enquanto esse espaço durar ou for reconstituído.
\end{abstract}

O trabalho do arqueólogo será o de reconstituir e tornar visível as condições de possibilidade de determinados jogos de verdade no interior da constituição do saber. A tarefa do arqueólogo é perscrutar o descontínuo, função que compreende vislumbrar o solo instável em que repousa a história. O descontínuo que é: “O fato de que em alguns anos, por vezes, uma cultura deixa de pensar como fizera até então e se põe a pensar outra coisa e de outro modo" (FOUCAULT, 2002, p. 69). O filósofo interroga-se então pelas modificações que tornaram possíveis alterações no próprio saber.

A arqueologia revela as regras anônimas que tornam possível um discurso com pretensão de verdade. Canguilhem apontou para o fato de as críticas ao livro de Foucault negligenciarem o termo "arqueologia" e o realocarem sob o termo "geologia". Para Canguilhem esse fato só faz mostrar o humanismo que anima as críticas feitas ao livro de 1966: "Fazer de Foucault uma espécie de geólogo é o mesmo que dizer que ele naturaliza a cultura retirando-lhe a história" (CANGUILHEM, 2012, p. 11). Se seguirmos a pista de Canguilhem, será justamente por recusar a ideia de um progresso que o trabalho de Foucault não será visto como histórico. Foucault deixa isso claro em seu prefácio: "Não se tratará, portanto, de conhecimentos descritos no seu progresso em direção a uma objetividade no qual nossa ciência de hoje pudesse enfim se reconhecer [...]" (FOUCAULT, 2002, p. XVIII). Mas é precisamente ao recolher as "descontinuidades na ordem empírica" que o arqueólogo faz emergir a história. A rede arqueológica que nos apresenta Foucault renova a ideia de 
temporalidade e, através da sucessão descontínua de enunciados, impede a reconstituição de um passado que é regido pela "presentificação" e acumulação.

O termo arqueologia diz exatamente o que ele quer dizer. É a condição de uma outra história, na qual o conceito de acontecimento é mantido, mas onde os acontecimentos atingem conceitos e não mais homens. Tal história deve, também ela, reconhecer cortes, como toda história, mas cortes diferentemente situados. (CANGUILHEM, 2012, p. 16).

A partir daí a relação entre sujeito e objeto muda: o pensamento não tem seu começo em uma subjetividade. Desse modo Foucault remove o sujeito de sua condição fundante. Ao retirar da consciência seu caráter constitutivo Foucault demonstra como o estabelecimento das ciências humanas não tem sua fundação no homem, mas em regras historicamente definidas. Segundo Deleuze, as ciências do homem:

se constituíram, quando o homem se "des-historicizou", quando as coisas (as palavras, os viventes, as produções) receberam uma historicidade que as liberava do homem e de sua representação. [...] Assim, as ciências do homem se constituíram imitando as novas ciências positivas da biologia, da economia política e da filologia. Para afirmar sua especificidade, elas restauraram a ordem da representação, acumulando-a com recursos do inconsciente. (DELEUZE, 2004, p. 127-128).

Foucault rejeita a ideia de uma história progressista que em suas análises enxergue algo como uma continuidade entre os encadeamentos históricos. Uma história traçada nesses moldes seria passível de ser reconstruída através de sínteses em torno dos homens que ligasse suas palavras e seus gestos. Essa história é o abrigo privilegiado da consciência. Sobre isso Foucault escreveria em resposta ao círculo de epistemologia em 1968 palavras quase idênticas as que publicaria mais tarde em sua introdução de A arqueologia do saber:

\begin{abstract}
A história contínua é o correlato da consciência: a garantia de que o que lhe escapa poderá lhe ser devolvido; a promessa de que todas essas coisas que a circundam e a ultrapassam lhe será dado um dia tornar a se apropriar delas, restaurar aí seu domínio, e encontrar o que é necessário chamar - atribuindo à palavra tudo o que ela tem de sobrecarga - sua morada. Querer fazer da análise histórica o discurso do continuo e fazer da consciência humana o tema originário de qualquer saber e de qualquer prática são as duas faces de um mesmo sistema de pensamento. (FOUCAULT, 2005, p. 85-86).
\end{abstract}

Uma vez que a enunciação não se relaciona a unidade de um sujeito - nem o sujeito fundante da racionalidade, nem o sujeito em sua função empírica - suas diversas modalidades não manifestam mais que sua dispersão nas variadas posições que o sujeito pode ocupar 
quando exerce um discurso. O que está em jogo aqui são as práticas discursivas que fazem possível esses planos nos quais o sujeito exerce um discurso e, não o estabelecimento de uma prática discursiva que seja a expressão de uma consciência idêntica a si. O sujeito em sua descontinuidade e em sua dispersão em relação a si mesmo é visto a partir de um espaço exterior ligado a uma rede de práticas.

Ao tratar de um conjunto de práticas específico Foucault recusa continuidades metahistóricas, ou seja, não observa nessas práticas um refinamento progressivo. A prática em Foucault, nos alerta Paul Veyne, não é uma instância descoberta por ele, ela é o que as pessoas fazem. Nesse sentido, Foucault não fala de coisa diferente da qual fala o historiador. No entanto:

\footnotetext{
compreende-se facilmente porque essa filosofia é difícil para nós: ela não se assemelha nem a Marx nem a Freud. A prática não é uma instância (como o Id freudiano) nem um primeiro motor (como a relação de produção), e, aliás, não há em Foucault nem instância nem primeiro motor (há, em contrapartida, uma matéria, como veremos). (VEYNE, 1982, p. 159-160).
}

Quando Foucault desnaturaliza determinados objetos, ele nos faz desconfiar da relação direta entre palavras e coisas. Governos, Estados, o Homem, são ilusões idealistas da semântica. Daí a querela com o marxismo: o discurso para Foucault não é ideologia, ele não quer dizer nada mais do que já diz. Desse modo, “cada época diz tudo o que pode dizer em função de suas condições de enunciado" (DELEUZE, 2013, p. 63). O que há são práticas discursivas que funcionam dentro das fronteiras arqueológicas. Assim, descontinuidades não são causadas ou exigidas por contradições internas ou forças externas. As regularidades arqueológicas também não são mantidas porque seriam ideologicamente funcionais.

\footnotetext{
Pois, desde que historicizamos nosso falso objeto natural, ele, agora, só é objeto para uma prática que o objetiva; é a prática com o objeto que ela se atribui que vem em primeiro lugar, é ela que é uma: a infraestrutura e a superestrutura, o interesse e a ideologia, etc., não passam de inúteis e desastrados cortes, operados numa prática que funcionava muito bem tal qual era e que volta a funcionar, novamente, muito bem; é, na verdade, a partir dela que as bordas do quadro se tornam inteligíveis. (VEYNE, 1982, p. 163).
}

A história como disciplina, afirma Foucault, constituía até então o último refúgio da ordem dialética, ou seja, ela serviria para encobrir as contradições racionais de uma história meta-narrativa. Uma história nesses moldes engloba os indivíduos em sua totalidade e faz deles agentes pouco conscientes. Ao apontar os limites desse modo de compreensão histórico 
Foucault teria despertado a fúria daqueles que viam nesse modelo uma forma de posicionamento político: "essa história, ao mesmo tempo projeto individual e totalidade, tornou-se para alguns intocável: recusar tal forma de dizer histórico seria atacar a grande causa da revolução" (FOUCAULT, 2001, p. 614).

Não serão poucos os que irão vislumbrar nas inovações de Foucault no campo da historiografia e da filosofia da história o cerne de um problema político. Jean Marie Domenach, católico e diretor da revista Esprit, dirá que o trabalho de Foucault soa como o manifesto de uma nova escola. Escreverá em 1967 a respeito de As palavras e as coisas e sobre o surgimento de uma "nova paixão" pelo conceito e pelo sistema. O texto de Domenach termina por conclamar: "Quantas perguntas poderíamos fazer! Quantas perguntas faremos!" (DOMENACH, 2003, p. 66). Dessas questões, feitas posteriormente no ano de 1968, Foucault responderá apenas uma, a saber:

Um pensamento que introduz a coação do sistema e a descontinuidade na história do espírito não tira ele todo fundamento de uma intervenção política progressiva? Não leva ao seguinte dilema: ou a aceitação do sistema, ou o apelo ao evento selvagem, a irrupção de uma violência exterior, única capaz de abalar o sistema? (FOUCAULT, 2001, p. 701).

O filósofo reconhece que essa questão toca o coração de sua obra e, que compreende justamente o ponto sobre o qual o trabalho teórico atual não pode se esquivar. Foucault responderá exaustivamente: ao sistema, ele oporá os critérios de formação; a continuidade oporá a descontinuidade; à história do espírito dará lugar a história do discurso. Sua crítica à história passará por todas essas questões. Segundo ele, um discurso poderá valer-se de dois tipos de recursos para tentar restituir a totalidade de sua história, a saber, o recurso históricotranscendental e o recurso empírico ou psicológico. O primeiro trata-se de enxergar em todo nascimento histórico uma fundação originária que imprimisse um telos a história da humanidade. O segundo recurso trataria de procurar o fundador, o que ele quis dizer, quais os significados de seu discurso. Essas são características de uma história totalizante que tratam de um "progresso da razão" ou de um "espírito de época". O conceito de episteme fará com que seja possível uma história que não é a do acúmulo de saberes. Não há uma mesma cronologia para diferentes discursos.

A maneira como Foucault tratava o problema da história anteriormente a obra de 1966 já indicava o posicionamento do filósofo contra uma história continuísta em que o passado se acumularia no presente. Foucault é aquele que "faz filosofia escrevendo histórias, não escreve 
uma história da filosofia" (MUCHAIL, 1995, p. 15). Isso quer dizer que obras como História da Loucura e $O$ nascimento da clínica não tratam a loucura e a medicina, respectivamente, como objetos preexistentes ou categorias intemporais. Se assim fosse, esses objetos teriam uma identidade imóvel que no decorrer da história humana teriam se aperfeiçoado devido ao "despertar de uma consciência". Desse modo, uma história dos saberes, seria o relato pelo qual a verdade espera ser descoberta, destituída dos obstáculos que a impediam de se revelar por meio da genialidade de algum sujeito.

Em entrevistas concedidas na década de 1960 Foucault ressalta as mudanças promovidas pela historiografia contemporânea ${ }^{4}$; ele lia com bons olhos os historiadores da escola dos Annales, como March Bloch, Fraçois Furet e Ferdinand Braudel. Esses historiadores haviam produzido algo de novo no debate historiográfico ao renunciarem a uma descrição global dos fatos, em que diferentes fenômenos no espaço-tempo são organizados de acordo com um princípio de coesão que pode se dar em torno de uma visão de mundo, de uma significação, de um "espírito de época", etc. Esse "modo de fazer histórico" característico da historiografia tradicional, em que o tempo é apreendido como sucessão de eventos que ganham inteligibilidade a partir de um encadeamento narrativo, era o que fazia ser possível interpretar os documentos e trabalhar com categorias gerais como feudalismo, luta de classes, etc.

No entanto, deve-se notar que o trabalho de Foucault foi visto na época por esses historiadores como uma contribuição à história das mentalidades. Outro fator importante a ser mencionado é o desconhecimento por parte dos annalistas dos avanços da epistemologia e da história dos sistemas de pensamento promovidos por Canguilhem e Bachelard a quem Foucault é tão tributário.

Destarte, ciente do debate que se promovia na historiografia na época da realização de seu livro, Foucault atribui a história um lugar privilegiado no último capítulo de As palavras e as coisas. Desde antes da constituição das ciências humanas a história exerceu certas funções de memória, exemplaridade, mito, etc. Essa história regulava o tempo dos homens e do mundo em um devir único. Dessa forma, a passagem do tempo teria conduzido os homens e todas as coisas em uma rede de acontecimentos sucessivos. Quando ocorre a mudança de episteme no século XIX essa coerência se desfaz. Descobre-se uma historicidade própria à natureza, ao trabalho e a linguagem. É nesse começo de século que o homem é "des-

\footnotetext{
${ }^{4}$ Sobre essas mudanças ver a entrevista concedida em 1967 Sur les façons d'écrire l'histoire e a entrevista concedida em 1969 Michel Foucault explique son dernier livre.
} 
historicizado": "porque fala, trabalha e vive, acha-se ele, em seu ser próprio, todo imbricado em histórias que não lhe são nem subordinadas nem homogêneas (FOUCAULT, 2002, p. $510)$.

É por isso que a história não tem bem um lugar dentro das ciências humanas, ou antes, seu lugar é de estranhamento. O papel que desempenha a história é semelhante à de uma "etnologia interna de nossa cultura e de nossa racionalidade, e encarnaria, consequentemente, a própria possibilidade de toda etnologia" (FOUCAULT, 2001, p. 626). Pois é a etnologia que coloca em cheque a ilusão transcendental de uma história continuísta. As relações entre natureza e cultura demonstram que não há um fio progressivo, teleológico, que conduza a humanidade a uma espécie de triunfo da racionalidade. O que mostra a etnologia, e serve de lição a filosofia da história, é que culturas heterogêneas passam por desenvolvimentos diferentes.

Enfim, pode-se dizer que o livro de Foucault, As palavras e as coisas, promove um incômodo nos estudos históricos ao desnudar a realidade e desnaturalizar objetos como a história. Ao comentar sobre esse livro, Deleuze dirá que uma nova imagem do pensamento se tornou possível através de sua "arqueologia de despedaçar ídolos" (DELEUZE, 2004, p. 127). As forças que aí se reúnem não cessarão, portanto, de liberar-se e de fazer surgir algo de novo na filosofia.

\section{REFERÊNCIAS}

CANGUILHEM, Georges. Michel Foucault: morte do homem ou esgotamento do cogito? Goiânia: edições Ricochete, 2012.

CASTEL, Robert. Introduction. In: MARCUSE, Herbert. Raison et Révolution. Paris: Minuit, 1968.

CASTRO, Edgardo. Vocabulário de Foucault: um percurso pelos seus temas, conceitos e autores. Belo Horizonte: Autêntica Editora, 2016.

DELEUZE, Gilles. O homem, uma existência duvidosa. In: DELEUZE, Gilles. A ilha deserta e outros textos. São Paulo: Iluminuras, 2004.

DELEUZE, Gilles. Foucault. São Paulo: Brasiliense, 2013.

DOMENACH, Jean-Marie. Une nouvelle passion. In: SMART, Barry. Michel Foucault critical assessments. London and New York: Routledge, 2003.

ERIBON, Didier. Michel Foucault, 1926-1984. São Paulo: Companhia das letras, 1990. 
FOUCAULT, Michel. Dits et écrits I. (1976-1988). DÉFERT, Daniel.; EWALD, François. (Eds.). Paris: Gallimard, 2001.

FOUCAULT, Michel. As palavras e as coisas. São Paulo: Martins Fontes, 2002.

FOUCAULT, Michel. História da loucura. São Paulo: Perspectiva, 2008.

FOUCAULT, Michel. A arqueologia do saber. Rio de Janeiro: Forense Universitária, 2014.

LEBRUN, Gérard. Notes sur la phénoménologie dans Le mots et le choses. In. Michel Foucault philosophe, Paris: Editions du Seil, 1989.

MUCHAIL, Salma Tannus. Foucault e a história da filosofia. Tempo Social, n. 7, 1995.

SARTRE, Jean Paul. Jean-Paul Sartre Répond. In: SMART, Barry. Michel Foucault critical assessments. London and New York: Routledge, 2003.

POTTE-BONNEVILLE, M. Michel Foucault, l'inquiétude de l'histoire. Paris: PUF, 2004.

VEYNE, Paul. Foucault revoluciona a história. In: VEYNE, Paul. Como se escreve a história. Brasília: Editora UNB, 1982. 